\title{
Del maniqueismo a la confluencia
}

En el año 1957, con mí título de médico bajo el brazo, marché a los Estados Unidos para formarme en psiquiatría clínica. Empecé a manejar los pocos medicamentos que se conocían por entonces. La cloropromazina surgió como nuestra panacea. Fue la línea divisoria que marcó la diferencia entre el horror de los manicomios y la tristeza de los pabellones de un hospital psiquiátrico. Pero, aún cuando reinaba (y todavía reina) la tristeza , a partir de entonces era posible contar con elementos efectivos para la lucha contra la enfermedad. Al mismo tiempo, mi residencia constaba de algunas clases de psicoanálisis. Sin embargo, mi pasión por el campo que había elegido aumentó cuando, por pura casualidad ( o no) tuve que sustituir a un residente que coordinaba un grupo terapéutico para alcohólicos. Me vi transitando, sin elementos teóricos suficientes, pero con la osadía de mis pocos años, en un terreno que me deslumbró. Me dispuse a aprender. Bion, Foulkes, Anthony, fueron guiándome hasta que, finalmente, Moreno me abrió las puertas del psicodrama.

Cuando regresé a la Argentina, en el año 1962, me asombró comprobar que las vertientes que yo había incorporado como siendo alternativas para un mismo objetivo, estaban no sólo separadas sino que en guerra declarada. ¿No eran acaso dos coyunturas para buscar aliviar, en conjunto, el sufrimiento humano? Esa disociación ya la había visto en Estados Unidos, pero de forma mucho menos evidente. La complejidad del alma humana necesita de un abordaje claro que pueda recurrir a ambos campos para poder tener éxito. Pero, en vez de esta confluencia encontré dos bandos atrincherados, cada uno profiriendo críticas destructivas hacia el campo contrario. «Pastilleros», decían unos, «charlatanes», proferían los otros. Cuando me definí como psicoterapeuta en la comunidad médica, no volví a ser invitado a participar en congresos de psiquiatría, y los visitadores de productos farmacéuticos dejaron de visitarme. Pertenecía al bando enemigo. Persistente, asistí al Congreso de Madrid, al de Hawai. Nunca había un espacio para mis trabajos. Dejé de ir, abandoné la lucha.

Claro que nuestra cultura, en todos los campos, incluido el nuestro, transita por la necesidad de una disociación ordenadora. Frente al caos, resulta de ayuda poner los aspectos peligrosos fuera de uno mismo. Los buenos y los malos sirven para definir desde los filmes de cowboy, hasta las diferentes ramas del saber, el deporte, el arte, la política. $\mathrm{Y}$, sin duda alguna, uno se incluye entre los buenos, los que tienen razón. Al «otro» se lo califica en el gueto de los indeseables. Pero, para proyectar el mito hay que mantenerse alejado. Y al maniqueísmo le sirve de ayuda el crear un código verbal que excluya a los no iniciados, con lo cual la brecha entre ambos mundos se va haciendo mas profunda. La palabra clave de nuestra cultura es «versus». Sicología versus siquiatría.

Claro que esto es tan sólo una mirada simple sobre una unidad de hecho. El alma humana es un todo y la enfermedad psíquica afecta al ser humano en su totalidad, a pesar de nuestros esfuerzos por disociarlo. Cuando el sufrimiento se torna insoportable, todo contacto humano se torna peligroso. Se forma una barrera, a veces infranqueable. ¿Cómo podemos querer aproximarnos a un ser que se encuentra en carne viva sin aumentar su dolor? Sólo la medicación corrige esta distancia y permite crear las condiciones necesarias para que alguien se disponga a revisar su mundo interno y relacional. También es cierto que sólo la medicación no ha de alterar las defensas erigidas para evitar o disminuir la intensidad del sufrimiento.

Si pensamos en confluencia y enriquecimiento recíproco, el concepto clave es el de la angustia. ¿No es acaso posible reconocer sus mecanismos neurofisiológicos de acción? ¿No es acaso posible determinar los mecanismos de defensa frente a la angustia, como modalidades de conductas defensivas perfectamente reconocibles? ¿No son acaso dos aspectos del mismo proceso? Cuerpo y alma coexisten, son, repito, una unidad indisoluble.

Otro concepto clave dirigido a buscar la confluencia es el de la relación terapéutica, denominado por el psicoanálisis en función de su aspecto patológico: la transferencia. Todo ser humano que sufre busca consuelo, sostén, comprensión. Administrar un medicamento no es un hecho aislado: su efectividad se sostiene en la confianza en el administrador. 
El que muchas veces debe aceptar la agresión, el rechazo o la idealización de su paciente sin auto-referirla. De la misma manera, cuando en la relación psicoterapéutica se pretende resolver un conflicto a través de las operaciones psicológicas sin comprender que una apropiada medicación ayudaría a llegar a una salida más rápida y eficiente, se está privando al paciente de la posibilidad de un recurso importante tan sólo por tratarse de un instrumento del «bando enemigo».

También el maniqueísmo nos divide a brasileños y argentinos. Es penosamente ínfimo el intercambio que existe entre nuestros países. Cultural, científico, artístico, económico. Vivimos idealizando el Norte. No niego la importancia de la actualización de descubrimientos que provienen de allá. ¿Cómo podría hacerlo si yo mismo aprendí lo que ellos generosamente me enseñaron? Pero nuestra realidad es otra. Y hay muchos profesionales de gran valor en nuestros países que tienen tantos conocimientos o más que los que provienen del Norte. Para aplicar los elementos descubiertos en el Primer
Mundo, hace falta un desarrollo económico y social que estamos lejos de tener.

Creo que fue en 1971 ó 72, que el Hospital das Clínicas me invitó a hacer una exhibición de psicodrama, seguido, o precedido, no recuerdo, de una exposición sobre el método de Moreno. Desde entonces comencé a viajar para formar profesionales en esta área. Ya hace 30 años que este país me recibe con sus brazos abiertos, su respeto y su cariño. Creo firmemente que nuestra salida proviene de la confluencia, de mirarnos y de disponernos a aprender de nuestras características, haciendo de nuestras diversidades un motivo de enriquecimiento. Saliendo de la falsa opción que proviene del empobrecedor "versus".

Dalmiro Manuel Bustos Instituto de Psicodrama JL Moreno

(Buenos Aires e São Paulo) International Association of Group Psychotherapy 